\title{
Lack of association of fragile histidine triad (FHIT) polymorphisms with lung cancer in the Korean population
}

\author{
Hae-Yun Jung $\cdot$ Jae Sook Sung $\cdot$ Young Mi Whang $\cdot$ Hyoung Doo Shin \\ Byung Lae Park · Jun Suk Kim · Sang Won Shin · Hee Yun Seo · Hwa Jung Sung • \\ In Keun Choi $\cdot$ Sang Cheul Oh $\cdot$ Jae Hong Seo $\cdot$ Yeul Hong Kim
}

Received: 31 January 2007/Accepted: 1 June 2007 / Published online: 4 July 2007

(C) The Japan Society of Human Genetics and Springer 2007

\begin{abstract}
The fragile histidine triad (FHIT), which was located on chromosome $3 \mathrm{p} 14.2$, was currently considered a promising candidate for a tumor suppressor gene. FHIT performed a crucial function in the tumorigenesis of lung cancer. The inactivation of FHIT via genetic alterations, including the chromosomal deletions and aberrant transcription, are often associated with lung cancer. In this study, the association between FHIT and lung cancer development was evaluated in a study of Korean patients. A total of 299 Korean lung cancer patients and 296 control subjects were recruited into this study. Direct DNA sequencing and TaqMan analysis were employed. Logistic regression analyses were conducted in order to characterize
\end{abstract}

This work was supported by a grant from the Korea Health 21 R\&D Project, Ministry of Health and Welfare, Republic of Korea (A010250), and intramural grants from the Korea National Institute of Health, Korea Center for Disease Control, Republic of Korea.

Electronic supplementary material The online version of this article (doi:10.1007/s10038-007-0169-7) contains supplementary material, which is available to authorized users.

H.-Y. Jung · J. S. Sung · Y. M. Whang · J. S. Kim ·

S. W. Shin $\cdot$ H. Y. Seo $\cdot$ H. J. Sung $\cdot$ I. K. Choi $\cdot$

S. C. Oh · J. H. Seo · Y. H. Kim $(\bowtie)$

Department of Internal Medicine and Brain Korea 21

Project for Biomedical Science, Genomic Research Center

for Lung and Breast/Ovarian Cancers,

Korea University College of Medicine,

126-1, Anam-dong 5Ga, Sungbuk-Gu,

Seoul 136-705, Korea

e-mail: yhk0215@korea.ac.kr

H. D. Shin - B. L. Park

Department of Genetic Epidemiology, SNP Genetics,

Inc., Rm 1407, 14th floor, Complex B,

WooLim Lion's Valley, 371-28 Gasan-Dong,

Geumcheon-Gu, Seoul, Korea the association between FHIT polymorphisms and lung cancer risk. Via direct sequencing in 24 Korean individuals, 27 sequence variants were identified. Eleven of these polymorphisms were selected for a larger scale genotyping $(n=595)$. Our finding indicated that the polymorphisms and haplotypes in the FHIT gene are not associated with lung cancer in the Korean population.

Keywords Fragile histidine triad (FHIT) - Korean population - Haplotypes · Lung cancer - Single nucleotide polymorphisms

\section{Introduction}

Lung cancer is one of the most lethal known malignancies and ranks the second highest in incidence in Korea (Shin et al. 2005). Lung carcinogenesis is a complex multistep process that involves a number of genetic changes in the tumor suppressor gene. The p53 and RB genes are frequently inactivated by genetic alterations including chromosomal deletions and mutations, whereas the p16 gene is inactivated not only as the result of genetic alterations, but also by transcriptional silencing resulting from hypermethlyation. The fragile histidine triad (FHIT) gene, a recently highlighted gene with regard to theses genetic alterations, has also been shown to be inactivated in a large proportion of cases of lung cancer development (Kohno and Yokota 1999; Wistuba et al. 2001). FHIT, which is located on chromosome 3 p14.2, is currently considered to be a promising candidate for a tumor suppressor gene (Pekarsky et al. 2002). The inactivation of FHIT has been determined to occur as the consequence of genetic alterations including the chromosomal deletions and aberrant transcription associated with a variety of cancers, such as colorectal, and lung cancer (Sozzi 
et al. 1997a, b; Yu et al. 2002). In addition, the majority of tumors and tumor-derived cell lines did not express or evidence reduced levels of FHIT (Druck et al. 1997; Hadaczek et al. 1998). Recently, Zanesi et al. reported that FHIT suppressed the tumorigenesis induced by $N$-nitrosomethylbenzylamine (NMBA) in FHIT-knockout mice (Zanesi et al. 2005). Specifically, the inactivation of the FHIT gene was profoundly associated with lung carcinogenesis. Sasaki et al. reported that reduced FHIT gene expression might occur early and play an important role in lung cancer tumorigenesis, and might also be correlated with the prognosis of lung cancer (Sasaki et al. 2006). Mao et al. reported that FHIT may be inactivated in tumor development, as in cases of smoking-associated lung cancer (Mao et al. 1997). However, no studies have yet been conducted to determine whether FHIT is associated with the risk of lung cancer risk.

In this study, we have attempted to characterize to the association between FHIT polymorphisms and the risk of lung cancer development in the Korean population, using genotype and haplotype analysis. Our finding indicated that FHIT polymorphisms and haplotypes are not significantly associated with lung cancer risk in the Korean population.

\section{Materials and methods}

\section{Study subjects}

The case-control study included 299 lung cancer patients and 296 healthy controls. The clinical characteristics of these groups have been summarized in Table 1. The eligible cases included all patients diagnosed with primary lung cancer at the Korea University Medical Center in Korea from October 2001 to April 2004. Lung cancer patients were recruited from the patient pool at the Genomic Research Center for Lung and Breast/Ovarian cancer, and the control subjects were randomly selected from a pool of healthy volunteers who had previously visited the Cardio-

Table 1 Demographic characteristics among lung cancer cases and controls

\begin{tabular}{llll}
\hline & Control & Case & $P$-value \\
\hline Number of subjects & 296 & 299 & \\
Age (years) & $51.8 \pm 13.2$ & $62.3 \pm 10.3$ & $<0.0001$ \\
Sex & & & \\
Male & 283 & 219 & $<0.0001$ \\
Female & 16 & 80 & \\
Smoking status & & & \\
Never & 90 & 76 & 0.332 \\
Current & 204 & 204 & \\
Unknown & 5 & 19 & \\
\hline
\end{tabular}

vascular Genome Center. A detailed questionnaire including questions regarding diet, smoking status, drinking status, lifestyle and medical history were completed by each of the patients and each of the controls with the help of a trained interviewer. With regard to the smoking status of the subjects, any subject who reported smoking at least once on a daily basis was considered to be a smoker for the purpose of this study. The samples of this study were all approved by the Institutional Review Board of the Korea University Medical Center.

\section{Sequencing analysis}

We sequenced all exons and their boundaries, in addition to the promoter region of the FHIT (OMIM No.601153) gene in 24 Korean DNA samples, using the ABI Prism 3700 DNA analyzer (Applied Biosystems, Foster City, CA). All primer sets for the amplification and sequencing analysis were designed on the basis of GenBank sequences (Supplement Table 1). The primer of the related information can be accessed at http://www.SNP-genetics.com. Sequence variants were confirmed by chromatograms.

Genotyping with fluorescence polarization detection

In order to genotype the polymorphic sites, all amplifying primers and probes were designed for the TaqMan system (Supplement Table 2). Primer Express (Applied Biosystems) was used to design both the PCR primers and the MGB TaqMan probes. One allelic probe was labeled with FAM dye and the other with fluorescent VIC dye. PCRs were conducted using TaqMan Universal Master Mix without UNG (Applied Biosystems) at PCR primer concentrations of $900 \mathrm{nM}$ and TaqMan MGB-probe concentrations of $200 \mathrm{nM}$. The reactions were carried out in a 384-well format, with a total reaction volume of $5 \mu \mathrm{l}$ using $20 \mathrm{ng}$ of genomic DNA. The plates were then placed in a thermal cycler (PE 9700, Applied Biosystems) and heated at $50^{\circ} \mathrm{C}$ for $2 \mathrm{~min}$ and $95^{\circ} \mathrm{C}$ for $10 \mathrm{~min}$ followed by 40 cycles of $95^{\circ} \mathrm{C}$ for $15 \mathrm{~s}$ and $60^{\circ} \mathrm{C}$ for $1 \mathrm{~min}$. The TaqMan assay plates were transferred to a Prism $7900 \mathrm{HT}$ instrument (Applied Biosystems) in which the fluorescence intensity in each well of the plate was read. Fluorescence data files from each plate were analyzed using automated software (SDS 2.1).

Statistical analysis

The $\chi 2$ tests were used to determine whether individual variants were in equilibrium at each locus in the population (Hardy-Weinberg equilibrium). Logistic regressions were used for calculating $P$ values controlling for age, sex and smoking status as covariate. $P$ values and odds ratios were 
Table 2 Frequencies of FHIT polymorphisms in Korean population

\begin{tabular}{|c|c|c|c|c|c|c|c|}
\hline \multirow[t]{2}{*}{ Loci } & \multirow[t]{2}{*}{ Position } & \multirow[t]{2}{*}{ Amino acid change } & \multirow[t]{2}{*}{ rs \# } & \multirow[t]{2}{*}{ Minor allele frequency } & \multirow[t]{2}{*}{ Heterozygosity } & \multicolumn{2}{|l|}{$\mathrm{HWE}^{\mathrm{a}}$} \\
\hline & & & & & & Case & Control \\
\hline$-716064 A>G$ & Promoter & & rs9862543 & 0.283 & 0.405 & - & 0.059 \\
\hline$-715859 A>T$ & Promoter & & rs1996958 & 0.172 & 0.284 & 0.992 & 0.878 \\
\hline -715850Tinsdel & Promoter & & novel & 0.043 & 0.083 & - & 0.977 \\
\hline$-715821 A>G$ & Promoter & & novel & 0.277 & 0.401 & 0.902 & 0.050 \\
\hline$-715523 T>C$ & Promoter & & rs9858223 & 0.173 & 0.287 & 0.906 & 0.995 \\
\hline$-714809 A>T$ & Promoter & & novel & 0.146 & 0.249 & - & 0.403 \\
\hline$-714528 G>C$ & Promoter & & rs9880846 & 0.439 & 0.492 & 0.064 & 0.091 \\
\hline$-714473 A>G$ & Promoter & & novel & 0.042 & 0.080 & - & 0.831 \\
\hline$-663800 T>C$ & Intron 1 & & rs 17064630 & 0.479 & 0.499 & - & 0.676 \\
\hline$-663794 C>T$ & Intron 1 & & novel & 0.021 & 0.041 & - & 0.917 \\
\hline$-663785 C>T$ & Intron 1 & & novel & 0.383 & 0.472 & 0.810 & 0.520 \\
\hline$-663500 G>T$ & Intron 2 & & novel & 0.063 & 0.117 & - & 0.744 \\
\hline$-663277 A>T$ & Intron 2 & & rs 17064628 & 0.354 & 0.457 & - & 0.993 \\
\hline$-285191 A>C$ & Intron 3 & & rs11130785 & 0.063 & 0.117 & - & 0.744 \\
\hline$-285185 C>T$ & Intron 3 & & novel & 0.167 & 0.278 & - & 0.327 \\
\hline$-285136 G>C$ & Intron 3 & & rs2205353 & 0.313 & 0.430 & - & 0.744 \\
\hline$-285126 G>A$ & Intron 3 & & rs2205352 & 0.254 & 0.379 & 0.936 & 0.868 \\
\hline$-284843 G>T$ & Intron 4 & & novel & 0.063 & 0.117 & - & 0.744 \\
\hline $523001 A>G$ & Intron 6 & & rs13067835 & 0.233 & 0.357 & 0.410 & 0.754 \\
\hline $525722 G>A$ & Intron 7 & & rs4679627 & 0.341 & 0.450 & 0.855 & 0.637 \\
\hline $525764 A>G$ & Intron 7 & & rs4679626 & 0.333 & 0.444 & - & 0.759 \\
\hline 525812AAAATinsdel & Intron 7 & & novel & 0.438 & 0.492 & - & 0.945 \\
\hline $614565 T>C$ & Exon 8 & Cys97Arg & rs1385816 & 0.394 & 0.477 & 0.659 & 0.401 \\
\hline $784503 G>T$ & Intron 8 & & rs 17061162 & 0.022 & 0.043 & - & 0.915 \\
\hline $784575 C>T$ & Intron 8 & & novel & 0.087 & 0.159 & - & 0.648 \\
\hline $784627 T>A$ & Intron 8 & & rs1683356 & 0.202 & 0.322 & 0.341 & 0.120 \\
\hline $784722 C>T$ & Exon 9 & Ala141Val & novel & 0.003 & 0.005 & 0.996 & . \\
\hline
\end{tabular}

${ }^{a} P$-values of deviation from among lung cancer and normal subjects

Bold face means SNPs genotyped in a larger population $(n=595)$ and plain faces were based on the sequencing data $(n=24)$

obtained using logistic regression. Heterozygosity for each locus with allele frequencies $p$ and $q(q=1-p)$ was derived using $H=1-p 2-q 2=2 p(1-p)$. We examined widely used measures of linkage disequilibrium between all pairs of bialleic loci; Lewontin's D' (| D'l) (Hedrick 1987) and $r^{2}$. Haplotypes and their frequencies were inferred using the algorithm developed by Stephens et al. (2001). Statistical methods of ANOVA and logistic regression were performed to analyze the ADJ-BMD levels and genotype distribution. The effective number of independent marker loci in FHIT was calculated to correct for multiple testing, using the software SNPSpD (http://www.genepi.qimr.edu.au/ general/daleN/SNPSpD/), which is based on the spectral decomposition $(\mathrm{SpD})$ of matrices of pair-wise $\mathrm{LD}$ between SNPs (Nyholt 2004). The resulting number of independent marker loci was applied to correct for multiple testing. Statistical powers were calculated using Statistical Power
Calculator (http://www.dssresearch.com/toolkit/spcalc/ power_p2.asp).

\section{Results}

By direct DNA sequencing in 24 individuals, we identified 27 genetic variants with exons and flanking regions of FHIT including the promoter regions. Eleven of the identified polymorphisms were selected for larger scale genotyping on the basis of locations, frequency, linkage disequilibrium (LD) and haplotype tagging status (Table 2; Fig. 1). Among 27 polymorphisms, -715859A $>\mathrm{T}, \quad-715821 \mathrm{~A}>\mathrm{G}, \quad-715523 \mathrm{~T}>\mathrm{C}, \quad-714528 \mathrm{G}>\mathrm{C}$, $-663785 \mathrm{C}>\mathrm{T},-285126 \mathrm{G}>\mathrm{A}, 523001 \mathrm{~A}>\mathrm{G}, 525722 \mathrm{G}$ $>\mathrm{A}, 614565 \mathrm{~T}>\mathrm{C}, 784627 \mathrm{~T}>\mathrm{A}$ and $784722 \mathrm{C}>\mathrm{T}$ of FHIT were selected and analyzed for a larger scale 
A Map of $F H I T$ (fragile histidine triad gene) on chromosome 3p14.2

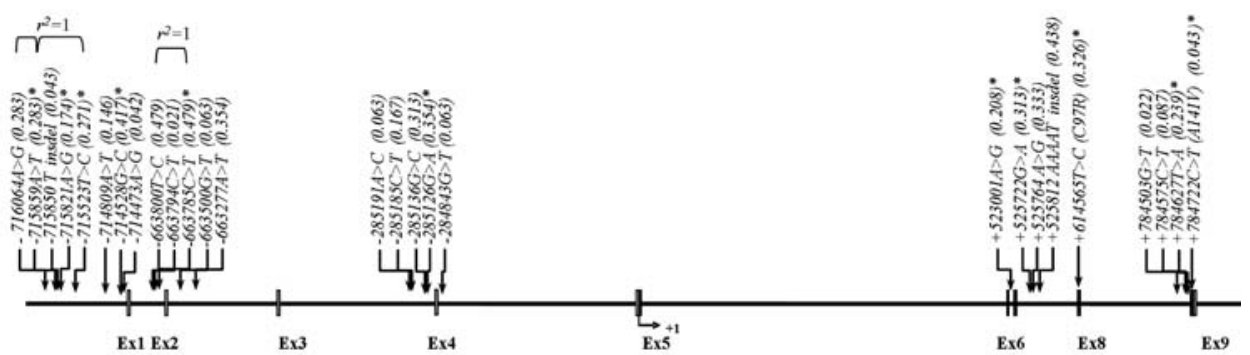

B Haplotype of FHIT

C LDs among FHIT polymorphisms
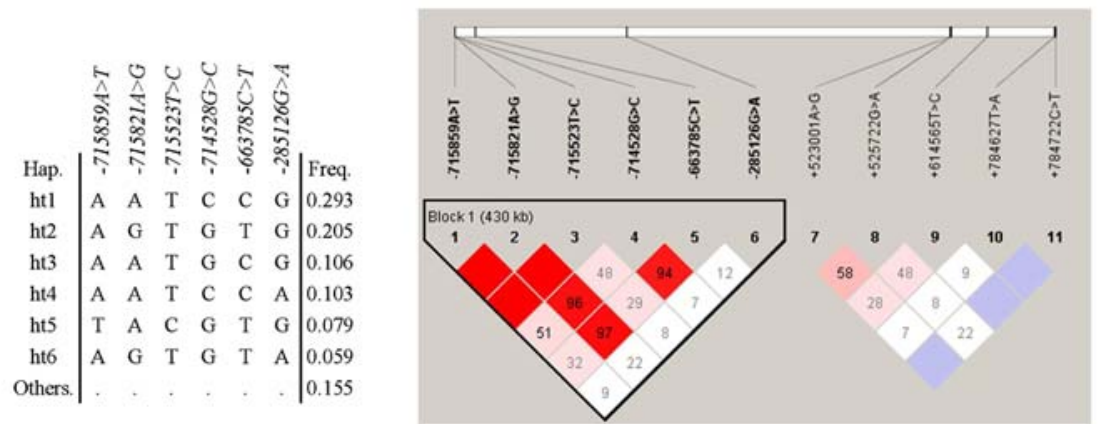

Fig. 1 Gene map, haplotypes and LD coefficients in FHIT. a Gene Map and SNPs in FHIT on chromosome 3p14.2 (reference sequence of FHIT: NT_022517.17). Coding exons are marked by black blocks and $5^{\prime}$ and $3^{\prime}$ UTR by white blocks. Asterisks indicate SNPs that were genotyped in a larger population. The frequencies of SNPs without larger scale genotyping were based on sequencing data $(n=24)$. The first base of the translation site was denoted as nucleotide +1 . b Haplotypes of FHIT. Haplotypes with frequency $>0.03$ are presented. c Linkage disequilibrium coefficient (ID'l) among FHIT SNPs. Only six SNPs, including $-715859 A>T,-715821 A>G$, $-715523 T>C,-714528 G>C,-663785 C>T$ and $-285126 G>A$, were used for construction of haplotype, because the rest of the polymorphisms were not in strong LD genotyping $(n=595)$ by considering their allele frequencies, haplotype-tagging status, and LDs among polymorphisms in Korean lung cancer patients and normal controls. Genotype frequencies for cases and controls were in Hardy-Weinberg equilibrium. Linkage disequilibrium coefficients $\left(\left|\mathrm{D}^{\prime}\right|\right)$ and $r^{2}$ among polymorphisms were also calculated (Fig. 1). Only six SNPs, including -715859 $A>T,-715821 A>G,-715523 T>C, \quad-714528 G>C$, $-663785 C>T$ and $-285126 G>A$, were used for construction of the haplotype, because the rest of the polymorphisms were not in strong LD. The allelic frequencies of each polymorphism and haplotype were compared between the patients and controls using logistic regression models (Table 3, Supplement Table 3). Logistic regression analyses revealed that FHIT $+525722 G>A$ showed marginal association with the lung cancer risk, but the association was lost after correction using SNPSpD. In the stratified analyses by age, gender and smoking status as well as the analyses of historical types of lung cancer, no significant associations were found between the FHIT polymorphisms and lung cancer risk (Supplement Tables 4 and 5).

\section{Discussion}

In this study, we hypothesized that FHIT polymorphisms were associated with lung cancer risk and that these polymorphisms might play a role as a predictor of lung cancer. We conducted preliminary polymorphism study for FHIT by sequencing at 24 samples and, for a further larger scale study, selected 11 polymorphisms of FHIT via genotyping a total of 595 samples, including 299 lung patients and 296 controls. Our finding indicated no association between the polymorphisms of the FHIT gene and lung cancer risk in the Korean population. When considering the absence of association and the limitation of our study, the small number of study subjects might affect the lack of association.

The tumor suppressor gene FHIT, which is located on chromosome $3 \mathrm{p} 14.2$, is associated with lung cancer. Several groups have reported that abnormalities of the FHIT gene and protein occur very frequently in cases of lung cancer (Fong et al. 1997; Sozzi et al. 1997a, b; Yanagisawa et al. 1996). However, very little research has thus far been focused on polymorphisms of the FHIT gene. In 1997, 
Table 3 Logistic analysis of FHIT polymorphisms with the risk of lung cancer while controling for age, sex and smoking status as covariates among lung cancer and normal subjects

\begin{tabular}{|c|c|c|c|c|c|c|c|c|c|}
\hline Loci & Genotype & Case & Control & $\begin{array}{l}\text { Crude OR } \\
(95 \% \text { CI })\end{array}$ & Crude $P$ & $\begin{array}{l}\text { Adjusted OR } \\
(95 \% \mathrm{CI})\end{array}$ & $P$ & $P$ corr & $\begin{array}{l}\text { Statistical } \\
\text { power }(\%)\end{array}$ \\
\hline \multirow[t]{3}{*}{$-715859 A>T$} & AA & $189(68.2 \%)$ & $203(69.3 \%)$ & & & & & & \\
\hline & AT & $79(28.5 \%)$ & $83(28.3 \%)$ & $1.07(0.79-1.46)$ & 0.67 & $0.97(0.66-1.43)$ & 0.89 & NS & 8.70 \\
\hline & $\mathrm{TT}$ & $9(3.3 \%)$ & $7(2.4 \%)$ & & & & & & \\
\hline \multirow{3}{*}{$-715821 A>G$} & $\mathrm{AA}$ & $151(54.1 \%)$ & $154(52.9 \%)$ & & & & & & \\
\hline & $\mathrm{AG}$ & $108(38.7 \%)$ & $104(35.7 \%)$ & $0.88(0.69-1.13)$ & 0.33 & $0.88(0.65-1.18)$ & 0.39 & NS & 17.70 \\
\hline & GG & $20(7.2 \%)$ & $33(11.3 \%)$ & & & & & & \\
\hline \multirow{3}{*}{$-715523 T>C$} & $\mathrm{TT}$ & $190(68.4 \%)$ & $201(68.8 \%)$ & & & & & & \\
\hline & $\mathrm{CT}$ & $80(28.8 \%)$ & $82(28.1 \%)$ & $1.01(0.74-1.37)$ & 0.95 & $0.91(0.63-1.33)$ & 0.63 & NS & 5.70 \\
\hline & $\mathrm{CC}$ & $8(2.9 \%)$ & $9(3.1 \%)$ & & & & & & \\
\hline \multirow[t]{3}{*}{$-714528 G>C$} & GG & $96(34.4 \%)$ & $102(34.8 \%)$ & & & & & & \\
\hline & CG & $121(43.4 \%)$ & $127(43.3 \%)$ & $1.01(0.81-1.27)$ & 0.90 & $1.06(0.81-1.37)$ & 0.68 & NS & 6.10 \\
\hline & $\mathrm{CC}$ & $62(22.2 \%)$ & $64(21.8 \%)$ & & & & & & \\
\hline \multirow[t]{3}{*}{$-663785 C>T$} & $\mathrm{CC}$ & $109(39.5 \%)$ & $113(38.7 \%)$ & & & & & & \\
\hline & $\mathrm{CT}$ & $128(46.4 \%)$ & $130(44.5 \%)$ & $0.93(0.74-1.18)$ & 0.56 & $0.90(0.68-1.19)$ & 0.47 & NS & 11.00 \\
\hline & $\mathrm{TT}$ & $39(14.1 \%)$ & $49(16.8 \%)$ & & & & & & \\
\hline \multirow[t]{3}{*}{$-285126 G>A$} & GG & $141(51.5 \%)$ & $169(58.1 \%)$ & & & & & & \\
\hline & $\mathrm{AG}$ & $109(39.8 \%)$ & $108(37.1 \%)$ & $1.32(1.01-1.72)$ & 0.04 & $1.12(0.81-1.55)$ & 0.50 & NS & 40.70 \\
\hline & AA & $24(8.8 \%)$ & $14(4.8 \%)$ & & & & & & \\
\hline \multirow[t]{3}{*}{$h t 1$} & $-1-$ & $147(53.1 \%)$ & $144(49.3 \%)$ & & & & & & \\
\hline & $-/ \mathrm{ht} 1$ & $107(38.6 \%)$ & $129(44.2 \%)$ & $0.95(0.73-1.24)$ & 0.71 & $1.00(0.73-1.37)$ & 1.00 & NS & 8.40 \\
\hline & ht1/ht1 & $23(8.3 \%)$ & $19(6.5 \%)$ & & & & & & \\
\hline \multirow[t]{3}{*}{$h t 2$} & $-1-$ & $179(64.6 \%)$ & $171(58.6 \%)$ & & & & & & \\
\hline & $-/ \mathrm{ht} 2$ & $86(31.1 \%)$ & $99(33.9 \%)$ & $0.78(0.59-1.02)$ & 0.07 & $0.83(0.59-1.15)$ & 0.26 & NS & 37.20 \\
\hline & $\mathrm{ht} 2 / \mathrm{ht} 2$ & $12(4.3 \%)$ & $22(7.5 \%)$ & & & & & & \\
\hline \multirow[t]{3}{*}{$h t 3$} & $-1-$ & $206(74.4 \%)$ & $231(79.1 \%)$ & & & & & & \\
\hline & $-/ \mathrm{ht} 3$ & $69(24.9 \%)$ & $57(19.5 \%)$ & $1.22(0.85-1.76)$ & 0.28 & $1.15(0.75-1.78)$ & 0.52 & NS & 19.00 \\
\hline & $\mathrm{ht} 3 / \mathrm{ht} 3$ & $2(0.7 \%)$ & $4(1.4 \%)$ & & & & & & \\
\hline \multirow[t]{3}{*}{$h t 4$} & $-1-$ & $218(78.7 \%)$ & $239(81.9 \%)$ & & & & & & \\
\hline & $-/ \mathrm{ht} 4$ & $52(18.8 \%)$ & $49(16.8 \%)$ & $1.23(0.86-1.77)$ & 0.26 & $1.31(0.86-2.00)$ & 0.21 & NS & 20.10 \\
\hline & $\mathrm{ht} 4 / \mathrm{ht} 4$ & $7(2.5 \%)$ & $4(1.4 \%)$ & & & & & & \\
\hline \multirow[t]{3}{*}{$h t 5$} & $-1-$ & $239(86.3 \%)$ & $253(86.6 \%)$ & & & & & & \\
\hline & $-/ \mathrm{ht} 5$ & $36(13.0 \%)$ & $38(13.0 \%)$ & $1.06(0.67-1.67)$ & 0.81 & $0.98(0.56-1.70)$ & 0.93 & NS & 7.30 \\
\hline & $\mathrm{ht} 5 / \mathrm{ht} 5$ & $2(0.7 \%)$ & $1(0.3 \%)$ & & & & & & \\
\hline \multirow[t]{3}{*}{$+523001 A>G$} & AA & $150(53.8 \%)$ & $179(61.3 \%)$ & & & & & & \\
\hline & $\mathrm{AG}$ & $114(40.9 \%)$ & $102(34.9 \%)$ & $1.31(0.99-1.74)$ & 0.06 & $1.36(0.96-1.92)$ & 0.08 & NS & 36.40 \\
\hline & GG & $15(5.4 \%)$ & $11(3.8 \%)$ & & & & & & \\
\hline \multirow[t]{3}{*}{$+525722 G>A$} & GG & $106(38.3 \%)$ & $135(46.2 \%)$ & & & & & & \\
\hline & $\mathrm{AG}$ & $134(48.4 \%)$ & $133(45.6 \%)$ & $1.36(1.06-1.75)$ & 0.02 & 1.43 (1.05-1.94) & 0.02 & NS & 49.60 \\
\hline & AA & $37(13.4 \%)$ & $24(8.2 \%)$ & & & & & & \\
\hline \multirow[t]{3}{*}{$+614565 T>C$} & TT & $107(38.6 \%)$ & $113(38.8 \%)$ & & & & & & \\
\hline & $\mathrm{CT}$ & $123(44.4 \%)$ & $127(43.6 \%)$ & $0.99(0.79-1.25)$ & 0.95 & $0.80(0.61-1.06)$ & 0.12 & NS & 5.30 \\
\hline & $\mathrm{CC}$ & $47(17.0 \%)$ & $51(17.5 \%)$ & & & & & & \\
\hline \multirow[t]{3}{*}{$+784627 T>A$} & $\mathrm{TT}$ & $165(67.4 \%)$ & $168(59.2 \%)$ & & & & & & \\
\hline & AT & $68(27.8 \%)$ & $108(38.0 \%)$ & $0.82(0.61-1.12)$ & 0.21 & $0.93(0.65-1.34)$ & 0.70 & NS & 21.30 \\
\hline & AA & $12(4.9 \%)$ & $8(2.8 \%)$ & & & & & & \\
\hline
\end{tabular}


Table 3 continued

\begin{tabular}{llllllll}
\hline Loci & Genotype & Case & Control & $\begin{array}{l}\text { Crude OR } \\
(95 \% \text { CI })\end{array}$ & $\begin{array}{l}\text { Crude } P \\
\text { Adjusted OR } \\
(95 \% \text { CI })\end{array}$ & $\begin{array}{c}P \\
P \text { corr }\end{array}$ & $\begin{array}{l}\text { Statistical } \\
\text { power (\%) }\end{array}$ \\
\hline$+784722 C>T$ & CC & $275(98.9 \%)$ & $292(100.0 \%)$ & & &. \\
& CT & $3(1.1 \%)$ & $0(0.0 \%)$ &. &. &. \\
& TT & $0(0.0 \%)$ & $0(0.0 \%)$ & & &. \\
\hline
\end{tabular}

Logistic regression models were used for calculating crude and adjusted odds ratios (95\% confidential interval) and corresponding $P$-values of codominant model for each SNP site and haplotype. Haplotypes in block 2 were not analyzed because SNPs in haplotype block 2 were not tightly linked

**To achieve the optimal correction for multiple testing of single-nucleotide polymorphisms (SNPs) in linkage disequilibrium (LD) with each other, the effective number of independent marker loci (10.4683) in FHIT was calculated using the software SNPSpD (http://genepi.qimr.edu.au/ general/daleN/SNPSpD/), on the basis of the spectral decomposition (SpD) of matrices of pair-wise LD between SNPs (Nyholt 2004)

Statistical powers were calculated using the Statistical Power Calculator (http://www.dssresearch. com/toolkit/spcalc/power_p2.asp)

Gemma et al. initially reported the discovery of a somatic mutation of codon 61 (threonine change to methionine) in exon 6 in human primary gastric cancer as the result of PCR single-strand conformation polymorphism analysis (Gemma et al. 1997). In 2003, only one group reported an association between FHIT polymorphisms and cancer risk. They suggested that codon 98 polymorphism in exon 8 of FHIT might be associated with an elevated risk of developing cervical cancer (Jee et al. 2003). Our group elected to investigate a possible association between polymorphisms of FHIT and risk of lung cancer. Our data indicated that the distribution of allele genotypes between all lung cancer and control subjects was not significantly different.

In summary, 27 sequence variants of FHIT were identified in 24 Korean individuals through direct sequencing. Eleven of these polymorphisms were selected for a larger scale genotyping $(n=595)$. We observed no significant difference in allele genotype distribution between the lung cancer cases and controls. Thus, we have concluded that no significant association exists between these polymorphisms and lung cancer risk in the Korean population.

\section{References}

Druck T, Hadaczek P, Fu TB, Ohta M, Siprashvili Z, Baffa R, Negrini M, Kastury K, Veronese ML, Rosen D, Rothstein J, McCue P, Cotticelli MG, Inoue H, Croce CM, Huebner K (1997) Structure and expression of the human FHIT gene in normal and tumor cells. Cancer Res 57(3):504-512

Fong KM, Biesterveld EJ, Virmani A, Wistuba I, Sekido Y, Bader SA, Ahmadian M, Ong ST, Rassool FV, Zimmerman PV, Giaccone G, Gazdar AF, Minna JD (1997) FHIT and FRA3B 3p14.2 allele loss are common in lung cancer and preneoplastic bronchial lesions and are associated with cancer-related FHIT cDNA splicing aberrations. Cancer Res 57(11):22562267

Gemma A, Hagiwara K, Ke Y, Burke LM, Khan MA, Nagashima M, Bennett WP, Harris CC (1997) FHIT mutations in human primary gastric cancer. Cancer Res 57(8):1435-1437
Hadaczek P, Siprashvili Z, Markiewski M, Domagala W, Druck T, McCue PA, Pekarsky Y, Ohta M, Huebner K, Lubinski J (1998) Absence or reduction of FHIT expression in most clear cell renal carcinomas. Cancer Res 58(14):2946-2951

Hedrick PW (1987) Gametic disequilibrium measures: proceed with caution. Genetics 117(2):331-341

Jee SH, Um SJ, Lee JE, Kim S, Kim JH, Lee SJ, Namkoong SE, Park JS (2003) The effect of codon 98 of the FHIT gene on cervical cancer in Korean women. Int $\mathrm{J}$ Gynecol Cancer 13(6):843-848

Kohno T, Yokota J (1999) How many tumor suppressor genes are involved in human lung carcinogenesis? Carcinogenesis 20(8):1403-1410

Mao L, Lee JS, Kurie JM, Fan YH, Lippman SM, Lee JJ, Ro JY, Broxson A, Yu R, Morice RC, Kemp BL, Khuri FR, Walsh GL, Hittelman WN, Hong WK (1997) Clonal genetic alterations in the lungs of current and former smokers. J Natl Cancer Inst $89(12): 857-862$

Nyholt DR (2004) A simple correction for multiple testing for singlenucleotide polymorphisms in linkage disequilibrium with each other. Am J Hum Genet 74(4):765-769

Pekarsky Y, Zanesi N, Palamarchuk A, Huebner K, Croce CM (2002) FHIT: from gene discovery to cancer treatment and prevention. Lancet Oncol 3(12):748-754

Sasaki H, Haneda H, Yukiue H, Kobayashi Y, Yano M, Fujii Y (2006) Decreased fragile histidine triad gene messenger RNA expression in lung cancer. Clin Lung Cancer 7(6):412-416

Shin HR, Won JY, Jung KW, Kong KW, Yim SH, Lee JK, Noh HI, Lee JK, Pisani P, Park JG (2005) Nationwide cancer incidence in Korea 1999-2001; first result using the National Cancer Incidence Database. Cancer Res Treat 37(6):325-331

Sozzi G, Sard L, De Gregorio L, Marchetti A, Musso K, Buttitta F, Tornielli S, Pellegrini S, Veronese ML, Manenti G, Incarbone M, Chella A, Angeletti CA, Pastorino U, Huebner K, Bevilaqua G, Pilotti S, Croce CM, Pierotti MA (1997a) Association between cigarette smoking and FHIT gene alterations in lung cancer. Cancer Res 57(11):2121-2123

Sozzi G, Tornielli S, Tagliabue E, Sard L, Pezzella F, Pastorino U, Minoletti F, Pilotti S, Ratcliffe C, Veronese ML, Goldstraw P, Huebner K, Croce CM, Pierotti MA (1997b) Absence of Fhit protein in primary lung tumors and cell lines with FHIT gene abnormalities. Cancer Res 57(23):5207-5212

Stephens M, Smith NJ, Donnelly P (2001) A new statistical method for haplotype reconstruction from population data. Am J Hum Genet 68(4):978-989

Wistuba II, Gazdar AF, Minna JD (2001) Molecular genetics of small cell lung carcinoma. Semin Oncol 28(2 Suppl 4):3-13 
Yanagisawa K, Kondo M, Osada H, Uchida K, Takagi K, Masuda A, Takahashi T, Takahashi T (1996) Molecular analysis of the FHIT gene at 3p14.2 in lung cancer cell lines. Cancer Res 56(24):5579-5582

Yu HG, Shun LB, Luo HS, Huang H, Yu BP, Yu JP, Meier JJ, Schrader H, Bastian A, Schmitz F, Schmidt WE (2002) Deletion of the FHIT gene in human colorectal cancer is independent of high-risk HPV infection. Int J Colorectal Dis 17(6):396-401

Zanesi N, Pekarsky Y, Croce CM (2005) A mouse model of the fragile gene FHIT: from carcinogenesis to gene therapy and cancer prevention. Mutat Res 591(1-2):103-109 